https://doi.org/10.48009/2_iis_2009_121-127

\title{
ONLINE MENTORING ACCEPTANCE BY WOMEN PROFESSIONALS
}

\author{
Regina A. Gibson, Gibson Research and Consulting gibsonfamily01@ comcast.net \\ Lloyd G. Gibson, Seton Hill University, gibson@setonhill.edu
}

\begin{abstract}
Online mentoring, also known as cybermentoring or e-mentoring, is an emerging phenomenon and information system improving the communication and behavior of women professionals, who cannot avail themselves of traditional modes of mentoring. However, like other new technology, online mentoring programs can be expensive to develop and implement. Thus, determining what acceptance factors related to online mentoring are important to women professionals can improve the chances that programs will be developed that appeal to these women. This study used a 2007 survey of 312 women professionals in the Southwestern Pennsylvania area and examined both demographic factors and attitudinal factors suggested by the Davis technology acceptance model and the Rogers diffusion of innovations theory. Results showed that demographic factors, such as age, education and profession, were statistically significant and that women who were younger, less educated, and self-employed were most accepting of online mentoring. In addition, analysis of two attitudinal factors suggested by Davis and Rogers, respectively, perceived usefulness and trialability were both positively correlated with online mentoring acceptance. These two factors may have implications with regard to the marketing and development of online mentoring programs for women professionals.
\end{abstract}

Keywords: Online mentoring, Cybermentoring, Technology acceptance, Diffusion of innovations theory, Women professionals

\section{INTRODUCTION}

Online mentoring, also known as e-mentoring or cybermentoring, is the practice that allows mentors and mentees (the mentored) to communicate by using the Internet on a one-to-one basis. The reason for this activity could be to discuss problems related to one's job, family, school, work, or other issues. In general, mentoring can be categorized in two ways: (a) career mentoring which includes sponsorship, exposure and visibility, coaching, protection, or providing challenging work assignments; and (b) psychosocial mentoring which includes role-modeling, acceptance and confirmation, counseling, and friendship [6]. It has been suggested that online mentoring may now be replacing the traditional form of mentoring, that is, face-to-face mentoring, for many women professionals [17].

Traditional mentoring and online mentoring are practices currently being adopted by several professional organizations, such as the Society of Women Engineers, the Service Corps of Retired Executives (SCORE), and the Women in Engineering Program Advocates Network (WEPAN), and universities, such as Northeastern University and the University of Vermont [8]. Sponsors of these formal mentoring programs provide access to professional networks and some degree of traditional face-to-face mentoring. This traditional concept of mentoring includes a nurturing and enduring relationship between a well-established professional and a more junior colleague $[17,19]$.

Costs of online mentoring can include the sponsoring organization's expenses associated with the professional time of the mentor and of the information systems personnel, and costs of any computer equipment, software, and Internet set-up. The mentor also invests his or her personal time at home in securing a good relationship with the mentee $[1,14]$. There are also costs to the mentee, possibly in terms of her personal and professional time and of her expenses associated with computer equipment and Internet setup.

The purpose of this study was to identify the factors that relate to or influence women professionals to accept online mentoring. If the factors that influence online mentoring adoption are known, then an organization which is interested in promoting the career advancement of women could use this information in order to better develop and implement formal mentoring programs. These factors should be 
studied because a lack of a mentoring relationship has been cited as one of the largest obstacles to women's progress in their careers [21].

Demographic factors examined in this study included age, income, profession, and mentoring-related factors which pertained to how the mentee or potential mentee was being mentored, such as her number of mentors, her mode of mentoring, her preferred mentoring site, and her computer usage. This study also considered the attitudinal factors suggested by the Davis [2] technology acceptance model (TAM) or extensions thereof, and the Rogers [18] diffusion of innovations theory. These attitudinal factors included the perceived usefulness, perceived reliability, perceived risk of the new technology, and the ease of use of the new technology.

No studies to date have been performed regarding acceptance factors for online mentoring adoption for either men or women. It should be pointed out that much of the recent literature pertaining to women professionals' adoption of online mentoring relates mostly to the effectiveness, as opposed to the acceptance, of the online mentoring programs for women professionals [15]. However, many studies have been performed recently pertaining to new technology acceptance. The theoretical model that has been used most frequently in these studies is the technology acceptance model (TAM), or some modified version of the TAM [2]. The diffusion of innovations theory or DOIT [18] has also been utilized in a number of studies [12]. These models suggest attitudinal factors, such as perceived usefulness of the technology, perceived risk, compatibility (with user values), and ease of use of the technology.

\section{RESEARCH METHODOLOGY}

This study focused on the following research question: What are the factors that influence the acceptance of online mentoring by women professionals? Based on prior findings of the acceptance studies of online technology regarding factors such as age, exposure to online technology, attitudinal factors, $[3,5,10]$ and entrepreneurial attitudes $[15,16]$, the research hypotheses to be tested are as follows:

$H_{l}$ : Younger and less-educated women professionals would be most likely to accept online mentoring.

$H_{2}$ : Women professionals with exposure to organized online programs would be most likely to accept online mentoring.

$H_{3}$ : Women entrepreneurs would be most likely to accept online mentoring.

$H_{4}$ : Attitudinal factors suggested by TAM and DOIT would affect the acceptance of online mentoring by women professionals.

A quantitative approach which had been successful in previous U. S. studies $[3,5,10]$ was employed using a survey designed to assess the impact of both demographic and attitudinal factors on the acceptance of online technology $[3,5,10]$. A total of 312 women from seven different women's professional groups, of which 115 were members of an entrepreneurship initiative group, in Southwestern Pennsylvania between August and November, 2007 participated in this project. All participants who considered themselves to be professionals completed a self-administered survey by either online $(86 \%)$ or hard-copy (14\%) method.

The three dependent variables that addressed the research question were: (a) the likelihood to use online mentoring informally, (b) the likelihood to use online mentoring formally, that is, with the sponsorship of a company or organization, and (c) the importance of online mentoring to the mentee in choosing a sponsoring organization. This study provided for multiple values based upon a 7-point Likert scale response to the questions corresponding to the likelihood of online mentoring use and a 5point Likert scale to the response to the question corresponding to the importance of online mentoring use. The responses ranged from definitely will not or not important at all to definitely will or most important.

Demographic and attitudinal factors were measured with the survey instrument developed by the Survey Research Center at the University of Michigan in 1999 and 2003 and used in subsequent online technology studies $[3,4,5,10]$. There were 16 independent demographic factors examined in this study. The demographic variables included (a) seven standard demographic, such as income, age, and marital status, (b) four mentoring- related, such as the number of mentors at home or work, site, and (c) five Internet/PC-related, such as Internet access and connection. In addition, responses to 17 attitudinal statements and their relationships to the dependent variables were examined. One-way ANOVA followed by the Bonferroni procedure was used to test for relationships between the demographic variables and the dependent variables, and correlation 
analysis followed by multiple linear regression was used to test for the relationships between the attitudinal variables and the dependent variables.

\section{RESULTS}

Demographic data were collected from 266 participants ( $85 \%$ of the sample). Details of the breakdown of this sample in Table 1 shows that $80 \%$ of the respondents were under 55 years-old, and $16 \%$ of the respondents were non-Caucasian. Almost 14\% of the respondents did not have a college degree. However, $94 \%$ of the participants used the Internet more than once per day (see Table 2), and as shown in Table 3, which details the mentoring behavior of the women professionals, $72 \%$ of 287 respondents wished to be mentored online.

$H_{l}$ proposed that younger and less-educated women professionals would be most likely to accept online mentoring. This hypothesis was supported. Results indicated that the two middle-age groups (35-44 and 45-54 years-old) had mean scores of 2.95 and 2.95, respectively, which were associated with the importance of the use of online mentoring to these groups, whereas the eldest groups (55-64 years-old and 65+ years-old) had mean scores of 2.61 and 1.38, respectively. One-way ANOVA indicated that these means differed significantly, $F(5,259)=2.44, p<$ .05. Similarly, a statistically significant difference, $F(2,257)=6.43, p<.01$, was found for the level of education; women professionals with no bachelor's degrees had a mean score of 3.37, whereas women professionals with post-graduate degrees had a mean score of 2.52. These scores were also associated with the importance of online mentoring use to these women.

$\mathrm{H}_{2}$ stated that women professionals with exposure to online programs would be most likely to accept online mentoring. This hypothesis was also supported. One-way ANOVA indicated that the mean scores associated with the likelihood of formal use of mentoring and the importance of use of mentoring were significantly higher for women who had been mentored online in the past 12 months, both formally and informally, The likelihood of women joining an organized mentoring program after being mentored online in an informal manner was particularly significant, $F(1,302)=94.05, p<.001$, with $\mathrm{M}=$ 3.12 for women who had not been informally mentored online versus $M=4.51$ for women who had been mentored informally online.

$H_{3}$ which proposed that women entrepreneurs would be more likely to accept online mentoring than women non-entrepreneurs was also supported. Mean scores $(\mathrm{M}=3.95$, associated with the likelihood of formal online mentoring use, and $\mathrm{M}=3.26$, associated with the importance of online mentoring use) of women entrepreneurs were significantly higher than other women's professional groups, $F(6$, $300)=5.33, p<.001$ and $F(6,302)=5.91, p<.001$, respectively.

$\mathrm{H}_{4}$ anticipated that the attitudinal factors suggested by TAM and DOIT would significantly influence the acceptance of online mentoring by women professionals. This hypothesis was supported by Pearson correlation analysis, $l r l \geq .195, p<.001$; $.194>l r l>.139, p<.01 ; l r l<.139, \quad p=.05 . H_{4}$ received greater support when two factors suggested by TAM and DOIT, respectively, perceived usefulness and trialability, were particularly significant in a subsequent step-wise multiple linear regression as shown in Table 4.

\section{CONCLUSIONS AND RECOMMENDATIONS}

Recent actual usage of online mentoring programs by women professionals was highly associated with the acceptance of online mentoring and thus is an important consideration in the marketing of formal online mentoring programs. Recent actual usage was directly related to the prior use of online technology, a variable considered to be the most significant factor in previous studies of online technology $[3,5,10]$. Prior use of online technology was also suggested as being an important factor in online mentoring studies [7].

This significance of this factor also suggests that the marketing of online mentoring to women professionals who had not participated in online mentoring will be considerably more difficult than to those women who had been mentored online. It is important to note that the most likely users of a formal online mentoring in the next year among this group are women who have been in a formal or organized online mentoring program in the past year. This is not surprising; however, it is important to note that these women entrepreneurs who are already satisfied with the program could promote it to other business women who have not been in a formal online mentoring program.

The findings pertaining to the attitudinal factors in this study were consistent with the theories and models developed as part of the TAM and DOIT. 
Four factors, perceived usefulness, perceived ease of use, perceived risk/security, and perceived reliability, were related to the TAM or a modified version of it. Trialability, or the opportunity to try to be mentored online, was related to the model developed from DOIT. In particular, trialability and perceived usefulness were significantly related to the three dependent variables associated with online mentoring acceptance, indicating that these factors should be carefully considered in marketing online mentoring programs to women professionals.

A comparison of these significant attitudinal factors with previous studies produces mixed results. Perceived usefulness, perceived risk/security and perceived reliability demonstrated significance in several technology acceptance studies $[2,3,5,11,12$, $10,20]$ and were suggested by online mentoring studies [6, 9, 13, 22]. Perceived ease of use also demonstrated significance in technology acceptance studies $[3,5,10]$ and was also suggested as a factor in an online mentoring study by Woodd [22]. However, trialability demonstrated significance only in the studies by Gibson [3] and by Lee, Lee, and Eastwood [11].

A successful implementation of online mentoring programs should also consider several attitudinal factors and statements that demonstrated statistical significance in this study. For example, the significance of perceived ease of use, associated with the statement "Being mentored online seems to be convenient," suggests that the promotional material or website pages for online mentoring should emphasize that use of the technology will be free from effort. This can be particularly true for working women and mothers [12] . In addition, the design of the online program should allow for (a) easy-to-use technology, such as a portable lap-top computer with high speed Internet access, and (b) a systematic matching of mentor and mentee in order to make the program more convenient for the user. In addition, usability studies would be beneficial to the implementation of the online mentoring programs.

Successful implementation should also consider the observability and trialability of the online mentoring program so that potential users can observe other women professionals being mentored and experiment with the program on a limited basis. These factors can be addressed by first arranging for the potential mentee to observe other mentees communicating with their mentors. Later the potential mentee could be introduced to a temporary mentor and, along with this mentor, the mentee could participate in the online program for two to three weeks. After a few weeks, if the mentor and mentee agree that the program is beneficial, then the online mentor/mentee arrangement can become permanent. This service, which in a sense offers an introductory trial period for the mentee to test the program, could be emphasized on the website of the sponsoring organization or in its promotional materials.

\section{REFERENCES}

1. Boneva, B., Kraut, R. \& Frohlich, D. (2001). Using e-mail for personal relationships: The difference gender makes. The American Behavioral Scientist, 45(3), 530-549.

2. Davis, F. D., Bagozzi, R., \& Warshaw, P. (1989). User acceptance of computer technology: A comparison of two theoretical models. Management Science, 35(8), 982-1003.

3. Gibson, L. G. (2007). Internet banking adoption by Chinese Americans. Published doctoral dissertation. Robert Morris University, Moon Township, Pennsylvania.

4. Gibson, R. A. (2008). Factors Affecting the Acceptance of Online Mentoring by Women Professionals. Published doctoral dissertation. Robert Morris University, Moon Township, Pennsylvania.

5. Hogarth, J., Kolodinsky, J. \& Gabor, T. (2006). Consumer payment choices: Paper, plastic - or electrons? Consumer Interests Annual, 52, 1-14.

6. Jandeska, K. E. \& Kraimer, M. L. (2005). Women's perceptions of organization culture, work attitudes, and role-modeling behavior. Journal of Managerial Issues, 17(4), 461478.

7. Johnson, N. M. \& Daire, A. P. (2007). School counselor implementation of an electronic mentoring (e-mentoring) program in a rural setting. Journal of Technology in Counseling, 5(1). Retrieved January 20, 2008, from http://jtc.colstate.edu/Vol5_1/Johnson.htm

8. Kasprisin, C. A., Single, P. B., Single, R. M., \& Muller, C. B. (2003). Building a better bridge: Testing e-training to improve e-mentoring programmes in higher education. Mentoring and Tutoring, 11, 67-78.

9. Knouse, S. B. (2001). Virtual mentors: Mentoring on the Internet. Journal of Employment Counseling, 38(4), 162-169.

10. Kolodinsky, J., Hogarth, J., \& Hilgert, M. (2004). The adoption of electronic banking technologies by U.S. consumers. The International Journal of Bank Marketing, 22(4/5), 238-259. 
11. Lee, E., Lee, J. \& Eastwood, D. (2003). A twostep estimation of consumer adoption of technology-based service innovations. The Journal of Consumer Affairs, 37(2), 256-282.

12. Lichtenstein, S. \& Williamson, K. (2006). Understanding consumer adoption of Internet banking: an interpretive study in the Australian banking context. Journal of Electronic Commerce Research, 7(2), 50-66.

13. Miller, H. \& Griffiths, M. (2005). E-Mentoring. In D. L. Dubois (Ed.), The handbook of youth mentoring (pp. 300-313). Thousand Oaks, CA: Sage Publications, Inc.

14. O’Neill, D. K., Wagner, R., \& Gomez, L. M. (1996, November). Online mentors: Experimenting in science class. Educational Leadership, 54(3), 39-42.

15. Perren, L. (2003). The role of e-mentoring in entrepreneurial education and support: A metareview of academic literature. Education \& Training, 45(8/9), 517-525.
16. Peterman, N. E. \& Kennedy, J. (2003). Enterprise education: Influencing students' perception of entrepreneurship. Entrepreneurship Theory \& Practice, 28(2), 129-144.

17. Ridout, S. (2006, January). Mentoring: Guided by the light. PT, 14(1), 42-44, 46-48.

18. Rogers, E. M. (1962). Diffusion of innovations. New York: Free Press.

19. Sparrow, S. (2006). Stuck in the middle with E. Training \& Coaching Today, 22-23.

20. Venkatesh, V. \& Davis, F. D. (2000). A theoretical extension of the technology acceptance model: four longitudinal field studies. Management Science, 46(2), 186-204.

21. Vonk, N. \& Kestin, J. (2007, April). Notes from the glass ceiling: So now what? Strategy, 72.

2 Woodd, M. (1999). The challenges of telementoring. Journal of European Industrial Training, 23(3), 140-144. 


\section{TABLES}

Table 1. Sample Demographics

\begin{tabular}{|c|c|c|}
\hline & $\mathbf{N}$ & $\% \mathbf{N}$ \\
\hline Age & 266 & \\
\hline $18-24$ & & 10.2 \\
\hline $25-34$ & & 19.5 \\
\hline $35-44$ & & 20.7 \\
\hline $45-54$ & & 29.7 \\
\hline $55-64$ & & 16.5 \\
\hline $65+$ & & 3.4 \\
\hline Race/Ethnicity & 266 & \\
\hline Hispanic & & 0.7 \\
\hline Native American & & 1.9 \\
\hline Asian American & & 3.8 \\
\hline Black/African American & & 9.4 \\
\hline Caucasian & & 84.2 \\
\hline Highest Level of Education & 262 & \\
\hline No Bachelor's Degree & & 13.7 \\
\hline Bachelor's Degree & & 40.5 \\
\hline Postgraduate or Prof. Degree & & 45.8 \\
\hline Annual Household Income & 227 & \\
\hline$\$ \quad 0-29,999$ & & 15.0 \\
\hline $30,000-49,999$ & & 13.2 \\
\hline $50,000-99,999$ & & 40.1 \\
\hline $100,000+$ & & 31.7 \\
\hline Marital Status & 263 & \\
\hline Married & & 61.6 \\
\hline Separated/Divorced/Widowed & & 14.8 \\
\hline Never Married & & 23.6 \\
\hline Table 2. Women Professional & $\begin{array}{l}\text { Jsage } \\
\mathbf{N}\end{array}$ & $\% \mathbf{N}$ \\
\hline PC Owner or Access & 310 & \\
\hline Yes & & 98.7 \\
\hline No & & 1.3 \\
\hline Internet Access & 305 & \\
\hline Home Plus & & 78.4 \\
\hline Hone Only & & 3.8 \\
\hline Other & & 7.5 \\
\hline No Access & & 0.3 \\
\hline Internet Connection Type & 309 & \\
\hline High Speed & & 96.8 \\
\hline Dial-up & & 3.2 \\
\hline Length of Time Using Internet & 311 & \\
\hline Less Than 1 Year & & 1.0 \\
\hline 2-3 Years & & 1.3 \\
\hline $3+$ Years & & 97.7 \\
\hline Frequency of Internet Use & 311 & \\
\hline Never & & 0.3 \\
\hline Less Than Once per Month & & 0.3 \\
\hline Once per Week & & 1.0 \\
\hline 3-5 Times per Week & & 1.0 \\
\hline Once per Day & & 3.2 \\
\hline More Than Once per Day & & 94.2 \\
\hline
\end{tabular}


Table 3. Women Professionals Mentoring Behavior

\begin{tabular}{|c|c|c|c|}
\hline & $\mathbf{N}$ & $\% \mathbf{N}$ & \\
\hline & & $\underline{\text { Yes }}$ & $\underline{\text { No }}$ \\
\hline Was Mentored Online in Last 12 Months & 309 & $\overline{21}$ & 79 \\
\hline \multicolumn{4}{|l|}{ Participated in an Organized Program if } \\
\hline Mentored & 146 & 22 & 78 \\
\hline Wish to be Mentored Online & 287 & 72 & 28 \\
\hline Likelihood of Being Mentored Online in & $307(\mathrm{~F})$ & Formally $(\mathrm{F})$ & Informally (I) \\
\hline Next Year & 303 (I) & & \\
\hline Definitely Not & & 9.8 & 7.6 \\
\hline Very Unlikely & & 31.6 & 27.7 \\
\hline Somewhat Unlikely & & 16.6 & 13.9 \\
\hline Even Chances & & 13.7 & 15.8 \\
\hline Somewhat Likely & & 13.0 & 15.5 \\
\hline Very Likely & & 10.1 & 11.2 \\
\hline Definitely Will & & 5.2 & 8.3 \\
\hline \\
\hline & 309 & & \\
\hline Not Important at All & & 26.6 & \\
\hline Somewhat Unimportant & & 7.4 & \\
\hline Neither Important nor Unimportant & & 34.6 & \\
\hline Somewhat Important & & 23.0 & \\
\hline Extremely Important & & 8.4 & \\
\hline
\end{tabular}

Table 4. Attitudinal Predictors From Regression Analysis of Online Mentoring Acceptance Measures

Likelihood of Formal Online Mentoring Use

$\mathrm{R}^{2}=.21 ; \mathrm{F}(3,264)=23.74 ; \mathrm{p}<.001$

I have the opportunity to be mentored online.

Std. Error

Beta

Online mentoring would help me better to

Likelihood of Informal Online Mentoring Use $\mathrm{R}^{2}=.34 ; \mathrm{F}(5,260)=26.76 ; \mathrm{p}<.001$

I have the opportunity to be mentored online.

Being mentored online seems to be convenient.

Online mentoring would help me better to $\quad .40$ solve my problems.

These mistakes are more difficult to correct online.

Importance of Online Mentoring Use

$\mathrm{R}^{2}=.31 ; \mathrm{F}(4,267)=30.29 ; \mathrm{p}<.001$

Being mentored online is the wave of the future.

Online mentoring would help me better to

$\begin{array}{lll}.37 & .10 & .24 \\ .34 & .09 & .23 \\ .28 & .09 & .18 \\ .16 & .06 & .14\end{array}$

solve my problems.

Online mentoring has many advantages that I can use.

I have seen how others are mentored online. 